Notre Dame Law School

NDLScholarship

Natural Law Forum

$1-1-1958$

\title{
On the Fusion of Fact and Value: A Reply to Professor Fuller
}

Ernest Nagel

Follow this and additional works at: http://scholarship.law.nd.edu/nd_naturallaw_forum Part of the Law Commons

\section{Recommended Citation}

Nagel, Ernest, "On the Fusion of Fact and Value: A Reply to Professor Fuller" (1958). Natural Law Forum. Paper 29. http://scholarship.law.nd.edu/nd_naturallaw_forum/29

This Article is brought to you for free and open access by NDLScholarship. It has been accepted for inclusion in Natural Law Forum by an authorized administrator of NDLScholarship. For more information, please contact lawdr@nd.edu. 


\section{ON THE FUSION OF FACT AND VALUE:}

\section{A REPLY TO PROFESSOR FULLER}

Ernest Nagel

Although the Doctrine of natural law is obviously not uncongenial to himself, Professor Fuller explicitly disclaims that in his contribution to this symposium he is arguing for any version of natural law theory. But unless I completely misunderstand him, his paper does make a vigorous plea for developing standards for evaluating the practices and the rules of the law, with the view to determining and clarifying the import of the legal order for human life. On the question of the paramount importance of such a double task, nothing divides me from him. No social institution, and certainly not the law, is exempt from moral criticism. And in my opinion it is one of the major, though not exclusive, tasks of an adequate philosophy of law to analyze proposed principles for assessing legal rules; to develop, in the light of such analysis, responsibly grounded criteria for evaluating the law; and to construct thereby the intellectual tools with the help of which we may form objective estimates of the worth of existing as well as of projected bodies of law.

It is a notorious fact, however, that on the basic issue as to the source and nature of standards of evaluation, philosophies of law are widely at variance, the variety of proposed standards and of their attempted validation being at least as great as the variety of moral theories in the history of thought. It is well to note, therefore, that the doctrine of natural law, either in its ancient or in its medieval formulations, is just one of many theories that have been advanced concerning the nature of the standards to be used. I must emphasize this obvious point, because in much recent literature the label "natural law doctrine" is often attached to almost any view which proposes objective standards for the moral evaluation of the law. In my opinion, this rather indiscriminate extension of the label debases the intellectual coinage, and produces little but confusion. But in any event, though I agree that the law is subject to moral criticism, and though I believe that the formal standards involved in such criticism may have an indefinitely large (if not universal) range of application, I wish explicitly to disavow any commitment, as a consequence of this belief, to what $I$ take to be the distinctive tenets of natural law theory. And since my function in this symposium is simply that 
of a commentator, I can only register my conviction that natural law doctrine supplies neither a tenable nor a useful basis for evaluating existing law.

But despite my agreement with what $I$ understand to be the aim of Professor Fuller's paper, I am frankly puzzled by the considerations he introduces to support his views; and I am not at all confident that I have grasped either his intent or his argument. I shall nevertheless try to show that 1) insofar as I do understand it, the contention upon which he places greatest weight is thoroughly unsound; 2) his implicit conception of purposive behavior and of human history is at least dubious; and 3 ) his premises are not obviously relevant for grounding his conclusions.

1) Professor Fuller begins his discussion by challenging what he calls the "truism" that "from what is nothing follows as to what ought to be." $\mathrm{He}$ bases his dissent on the claim that "in any interpretation of events which treats what is observed as purposive, fact and value merge," so that value judgments cannot be regarded as "something foreign to a purely factual account." (p. 69) Is this challenge of the dictum that what ought to be does not follow from what exists well taken?

a) The dictum may be, and indeed has been, interpreted to assert that statements of what is the case are always irrelevant to the determination of what ought to be. And if Professor Fuller finds the dictum so construed to be dubious, I must again admit my agreement with him. If, however, he is merely challenging the dictum when read this way, he has misunderstood many writers whom he has criticized for subscribing to the dictum, since they espouse the dictum with a different interpretation of it. There certainly have been thinkers in recent years, even among the group of so-called legal "realists" and "positivists," who, though they profess the truism Professor Fuller is questioning, also maintain that responsible claims as to what ought to be must be supported by empirical study of the physical, biological, and social requirements of human life, and of the import of various institutions and regulations. Within the framework of such a moral theory, judgments as to what ought to be done do not follow logically from judgments as to what is actual; nevertheless, judgments asserting what ought to be are conceived as hypotheses about ways of resolving conflicting needs and interests. Accordingly, though on this view there is a sharp distinction between what is and what ought to be, value judgments are not thereby regarded as foreign intrusions into the study of human behavior.

b) It seems unlikely, however, that Professor Fuller is claiming no more than that judgments of fact are relevant to the determination of the adequacy of judgments of value, For as he explicitly says, he believes that in the 
examination of purposive behavior the notions of fact and value merge, so that a sharp distinction between judgments of fact and judgments of value cannot be made. But I do not find this contention plausible. On the contrary, Professor Fuller's own example seems to me to reinforce the distinction he thinks he is undermining; and his discussion, insofar as I understand it, appears to me to establish what is at best a tautology.

i) I shall first try to show that Professor Fuller's illustration presupposes the distinction between fact and value. According to him, when we once grasp the purpose which actuates a boy's manipulation of a clam, we discover in the structure of events as they unroll "an element of value"; and we can anticipate whether a certain action will be continued or not, because the action is recognized as good or as bad as a means for achieving the boy's objective. But just how does the example show that fact and value merge? In characterizing one of the boy's actions as "bad," it is surely pertinent to ask what it is we are so characterizing; and the answer must inevitably be descriptive of a fact. Indeed, unless a careful factual account can be given, one which is not colored by a surreptitious value imputation, we cannot judge competently whether the act does have the value attributed to it. When a physician prescribes penicillin as good for the cure of pneumonia, his value judgment, if it is competently grounded, is predicated on the assumption that he knows the condition of the patient as well as the effects of the drug on the human body; and though the physician may tacitly assume the correctness of the factual data, and may be uninterested in the descriptive facts except insofar as they bear upon his aim to effect a cure, it is imperative to distinguish clearly between what the facts are and an evaluation of them with respect to a certain end. Similarly, when in a court of law an individual is on trial for a crime, it is imperative to establish with utmost care just what the person did do, before a judgment is rendered on the goodness or badness of his acts in relation to the crime with which he is charged. It is undoubtedly true that many people do not distinguish their value imputations from the facts they are judging; but this is surely regrettable, and does not mean that the distinction cannot be made. In short, I do not find that Professor Fuller has given us any reasons for holding that in discussing purposive behavior the distinction between judgments of fact and of value breaks down, or that in such contexts fact and value merge.

ii) I next want to argue that in claiming an element of "intrinsic" value to be present in situations involving purposive behavior, Professor Fuller is asserting what is at best a tautology. When we are dealing with such behavior, we are by hypothesis concerned with ascertaining among other things 
whether, and if so with what degree of effectiveness, a given set of actions contributes to the realization of some assumed goal. It would therefore be self-contradictory to maintain, on the one hand, that we are seeking to determine just what an act achieves in bringing about a certain end, and to deny, on the other hand, that in such an inquiry value judgments do occur because they are irrelevant. Indeed, whenever we are analyzing the operations of a system which is assumed to be a teleological or "goal-directed" one, whether the system is a purely physical one or involves the presence of human agents, value judgments necessarily occur with respect to the roles played by the component "parts" of the system in maintaining or progressively realizing specified "goals." All this, however, seems to me logically truistic, for it simply explicates what it is we are doing when we are studying purposive or other forms of teleological behavior. But although Professor Fuller maintains that in such inquiries the merging of fact and value can be demonstrated, I hope to have said enough to show that on this point he is mistaken. Moreover, while he explicitly notes the objection to his view that the actions he is considering are not "intrinsically" valuable, but possess a value only insofar as they are functional or.dysfunctional in relation to specified ends, I have unfortunately not succeeded in ascertaining how he thinks he has turned the force of this objection.

2) There is, however, another thesis for which Professor Fuller also breaks a lance, but which is far from being a truistic one. He reminds us that the structure of purposive action is not constituted by a set of discrete happenings. He notes that even in the case of the working out of what is ostensibly an "immediate" or "single" purpose (as in the example of the boy manipulating a clam), a "congeries of related purposes" is in general operative, and that in consequence we cannot hope to understand the course of purposive action "simply by perceiving at any given moment whatever immediate purpose is then being pursued." (p. 70) So far these observations seem to me sound. But is the only alternative to an atomistic conception of human purposes and goals one which assumes that all immediate purposes, whether individual or social, are elements in a temporally developing but organically integrated system of ends? While I am not confident that I have understood the positive import of Professor Fuller's rejection of the atomistic conception, it is some such view as this which is suggested by much that he says.

[He declares, for example, that "any single human purpose $\ldots$ is an incomplete thing when severed from the total system of which it forms a part," (p. 71) and he also says that the meaning of any single purpose 
is always controlled by the "latent" purposes in interaction with it. Again, he asserts that in what he regards as the somewhat "mysterious" process wherein we determine "what we really want," we frequently consult with friends and so engage in a process of the "collaborative articulation of shared purposes"; (p. 73) and he cites the history of the common law as an example which teaches "how a social institution may derive its integrity and vitality from the same spirit of consultation as that which animates the discussion of two friends sharing a problem together." (p.74)]

Such a view, in any case, I find incredible, for it is incompatible with the identifiable facts of contemporary human experience, as well as with the known character of human history. There is much evidence to show that individuals and groups sometimes engage in a collaborative process in which common goals are established and articulated. There is no evidence that the total life of a human individual or of the human race is a process in which a shared common purpose is gradually though imperfectly created and unfolded. (Indeed, I cannot make clear sense of the supposition that what is loosely called "human history" is a single process.) I cannot even see in the history of the common law the operation of such a process; and I find it gratuitous to assume that the manner in which legal precedents were used in courts of common law in the nineteenth century for settling historically novel issues, would have been regarded by seventeenth century common law judges as implementations of a common end-in-view, where that end-in-view was "then out of view because not stirred into active consciousness by the facts of the case being decided." (p. 74) An end-in-view that is nevertheless not explicitly present in active consciousness seems to me just a myth, the product of the same type of dubious reasoning which assumes that the outcome of a complex series of changes can be explained only by postulating the outcome as already "implicitly present" in the initial terms of the series.

I can on this occasion only assert dogmatically what seems to me obvious - that in actuality there are competing and even incompatible human objectives, both individual and social, and that the task of moral theory is to provide standards with the help of which such conflicts may in some measure be adjusted. Accordingly, the mere existence of purposes and goals does not settle the question as to what ought to be done when a moral problem arises. It is chiefly for this reason that the distinction between what is actual fact and what ought to be is both unavoidable and useful when moral deliberation is initiated. I should like to add, however, that though the assumption of a universally shared if tacit common human purpose is dubious, it does not follow that men with different "ultimate" objectives cannot live 
amicably together and cooperate effectively for the attainment of their diverse ends. The assumption that it does follow is just a mistake in analysis.

3) This brings me to my final difficulty with Professor Fuller's essay. I am entirely unclear how his claim concerning the fusion of fact and value, even if the claim were sound, is relevant to his belief in the possibility of an objective moral evaluation of the law, or what light that alleged fusion throws on the nature and authority of the principles to be employed in such evaluation. The norms for a responsible assessment of legal rules, so I am supposing, must codify the more enduring and general objectives of the institution of the law, on the basis of available though corrigible knowledge about individual and social needs. Such norms therefore provide a measure for judging the adequacy of existing legal arrangements and practices, and they supply general directives for estimating the worth of particular legal rules as well as for introducing needed changes in the law. These norms may not be invariant for all societies and for all times without thereby losing their authority for a given social order; and a philosophy of law sensitive to innovations in that order and to fresh knowledge about human needs and capacities will suitably modify its principles of evaluation. But implicit in this conception of the office of standards of criticism is the distinction between fact and value; and I do not see how, by denying that distinction, one can hope either to establish the need for such standards or to clarify their nature and function. A fully embodied ideal ceases to be an ideal; and an action is purposive only as long as the ends sought by that action have not already been achieved. It is only by a prolepsis that the qualities which may characterize the possible outcome of purposive behavior can be predicated as intrinsic features of that behavior. Accordingly, I find little but confusion in fuzzing the distinction between fact and value. By refusing to make that distinction we not only contribute nothing to the problem concerning the nature and role of principles of moral criticism. My fear is that by refusing to make it, or even by softening its edges, we are well on our way to ignoring that there is such a problem at all. 